\title{
Predictors of Postoperative Outcome After General Surgical Procedures in Patients With Congenital Heart Disease
}

\author{
By Hani A. Hennein, Eric N. Mendeloff, Robert E. Cilley, Edward L. Bove, and Arnold G. Coran \\ Ann Arbor, Michigan
}

\begin{abstract}
- This study was undertaken to evaluate factors predictive of postoperative outcome after general surgical (GS) procedures in patients with congenital heart disease (CHD). All patients with a diagnosis of CHD who underwent a GS procedure under general anesthesia during a consecutive 10-year period were considered eligible for the study. The congenital heart defect was classified as either simple (ASD, VSD, PDA) or complex (endocardial cushion defects, transposition of the great vessels, tetralogy of Fallot), and the GS procedure as either major (intraperitoneal, intrathoracic, or vascular reconstructive) or minor (inguinal herniorrhaphy, vascular access). The overall mortality rate for the patient population was 12\% (27 deaths among 226 procedures), minor procedures being associated with a $3 \%$ mortality rate (2 of 70 procedures), and major procedures with a $16 \%$ mortality rate (25 of 156 procedures). Incremental risk factors for mortality included a preoperative American Society of Anesthesiologists' (ASA) physical status class of IV or higher $(P=.0003)$, a preoperative in-hospital stay of 10 or more days $(P=.004)$, birth at a tertiary care center $(P=.04)$, and emergency operations $\{P=.05\}$. In the subgroup of patients less than 6 months old, weight of less than $2.4 \mathrm{~kg}$ at the time of surgery and a 1-minute Apgar score of less than 4 were additional independent risk factors $(P=.04$ and .01 , respectively). By logistic analysis, previous corrective cardiac procedures, whether complete or palliative, did not significantly alter the postoperative outcome. The authors conclude that physiologically well-compensated patients with CHD can undergo elective operations at a low operative risk; however, poorly compensated patients undergoing urgent or emergent operations are at high risk. Previous corrective cardiac procedures may improve the overall outcome if the physiological state of the patient could be improved.

Copyright $\odot 1994$ by W.B. Saunders Company
\end{abstract}

INDEX WORDS: Congenital heart disease, risk factors for general surgical procedures.

CEVERAL LANDMARK studies have been pub$\mathcal{N}$ lished concerning cardiac risk factors in adult patients undergoing noncardiac surgical procedures. ${ }^{1}$ However, no known study has evaluated the presence of congenital heart surgery as a risk factor for noncardiac surgery. Only a few institutions possess the clinical volume of pediatric general surgical patients with congenital heart disease who undergo general surgical operations, thus enabling such an

From the Pediatric General and Cardiac Surgical Senvices, Mott Children's Hospital, University of Michigan Hospitals, Ann Arbor, MI. Date accepted: November 9, 1993.

Address reprint requests to Amold G. Coran, MD, L2110 Women's

Hospital, University of Michigan Hospitals, Ann Arbor, MI 48109.

Copyright $\odot 1994$ by W.B. Saunders Company

0022-3468/94/2907-0004\$03.00/0 analysis. The purpose of the present study was to evaluate the presence of congenital heart disease (CHD) as a risk factor in patients undergoing general surgical procedures, and to examine whether previous corrective repair of the underlying cardiac defect significantly altered the clinical outcome.

\section{MATERIALS AND METHODS}

All patients with a diagnosis of CHD who underwent a general surgical (GS) procedure performed under general anesthesia by staff members of the Pediatric Surgical Service during a consecutive 10-year period (ending in June 1991) were considered eligible for the study. Excluded from the study were patients whose GS procedure consisted solely of cannulation for extracorporeal membrane oxygenation (ECMO), and patients whose CHD diagnosis pertained solely that of persistent fetal circulation. Also excluded were patients undergoing neurosurgical, otolaryngological, urologic, orthopedic, or other subspeciality procedures. Characteristic variables obtained from a review of the charts are shown in Table 1. For patients who underwent more than one GS procedure during a single hospitalization, only the procedure for which the patient was admitted, or the earliest major procedure performed during that hospitalization, was considered for analysis. The American Society of Anesthesiologists' (ASA) physical status classes were defined as follows: class I, healthy patient; class II, patient with a mild systemic disease; class III, patient with a severe systemic disease that limits activity but is not incapacitating; class IV, patient with an incapacitating systemic disease that is a constant threat to life; and class V, a moribund patient not expected to survive 24 hours with or without operation. Postoperative death was defined as that which occurred within 30 days of the operative procedure, or that which occurred at any time during the hospitalization, after completion of the GS procedure.

Statistical analysis was performed using commercially available software (SAS Institute, Cary, NC) on personal computers (IBM Corp). Frequency distributions were analyzed using MantelHaenszel $\chi^{2}$ analysis, and differences in means by the $t$ test and analysis of variance. Stepwise regression analysis was used to test for statistical independence.

\section{RESULTS}

A total of 226 general surgical operations were performed on 208 patients with CHD over the course of the study period. Follow-up data were obtained for 201 patients $(96 \%)$. The mean age $( \pm$ SEM) of the study population was $2.2 \pm 0.3$ years, the mean weight was $8.2 \pm 0.8 \mathrm{~kg}$, and the mean ASA score was $2.98 \pm$ 0.06 . The average length of hospitalization before surgery was $17 \pm 3$ days; the length of stay after surgery was $24 \pm 3$ days. Eighty-four patients were on an average of $2.1 \pm 0.1$ cardiac medications at the time of surgery. Forty-seven percent (107) of the patients were referred from the outpatient depart- 
Table 1. Profile of the 226 General Surgical Procedures

\begin{tabular}{|c|c|c|c|}
\hline & \multicolumn{2}{|c|}{ Patient Age } & \multirow[b]{2}{*}{$P$ Value } \\
\hline & $\leq 6 \mathrm{Mo}$ & $>6 \mathrm{Mo}$ & \\
\hline \multicolumn{4}{|l|}{ General patient characteristics } \\
\hline No. of operations & 138 & 88 & \\
\hline No. of deaths $(\%)$ & $21(15)$ & $6(7)$ & .05 \\
\hline Gestation (wk) & $35 \pm 1$ & $35 \pm 1$ & NS \\
\hline Apgar at $1 \mathrm{~min}$ & $5.4 \pm 0.2$ & $6.2 \pm 0.8$ & NS \\
\hline Apgar at $5 \mathrm{~min}$ & $7.2 \pm 0.2$ & $7.8 \pm 0.5$ & NS \\
\hline Age at time of surgery $(\mathrm{yr})$ & $0.13 \pm 0.01$ & $5.4 \pm 0.6$ & $<.0001$ \\
\hline Weight at time of surgery $(\mathrm{kg})$ & $3.2 \pm 0.1$ & $16.7 \pm 1.9$ & $<.0001$ \\
\hline ASA score & $3.1 \pm 0.1$ & $2.7 \pm 0.1$ & .002 \\
\hline Percentage of males & 59 & 63 & NS \\
\hline \multicolumn{4}{|l|}{ Urgency of operation (\%) } \\
\hline Elective & 17 & 64 & \multirow{3}{*}{$<.0001$} \\
\hline Urgent & 5 & 11 & \\
\hline Emergent & 78 & 25 & \\
\hline \multicolumn{4}{|l|}{ Admission pattern $(\%)$} \\
\hline High-risk birth center & 20 & 01 & \multirow{4}{*}{$<.0001$} \\
\hline Emergency room & 2 & 6 & \\
\hline Outpatient & 25 & 82 & \\
\hline Referring hospital & 53 & 12 & \\
\hline \multicolumn{4}{|c|}{ Characteristics of the congenital heart defect } \\
\hline Frequency of cyanosis $(\%)$ & 12 & 19 & NS \\
\hline Frequency of complex lesion $(\%)$ & 26 & 44 & .007 \\
\hline No. of cardiac medications & $2.1 \pm 0.1$ & $2.0 \pm 0.2$ & NS \\
\hline \multicolumn{4}{|l|}{ Correction of $\mathrm{CHD}$ lesion $(\%)$} \\
\hline None & 43 & $33 \mid$ & \multirow{3}{*}{ NS } \\
\hline Palliative & 14 & 22 & \\
\hline Complete & 43 & 45 & \\
\hline \multicolumn{4}{|c|}{ Characteristics of the general surgical procedure } \\
\hline Major procedure $(\%)$ & 72 & 65 & NS \\
\hline LOS before procedure $\{d\}$ & $21 \pm 3$ & $11 \pm 4$ & .06 \\
\hline LOS after procedure (d) & $34 \pm 4$ & $9 \pm 2$ & $<.0001$ \\
\hline \multicolumn{4}{|l|}{ Disposition $(\%)$} \\
\hline Home & 79 & 92 & \multirow{3}{*}{.02} \\
\hline Transfer & 5 & 1 & \\
\hline Death & 16 & 7 & \\
\hline
\end{tabular}

Abbreviations: LOS, length of stay; NS, not significant.

ment. The others were transferred from an outside hospital $(84 ; 37 \%)$, were born at a tertiary care center $(27 ; 12 \%)$, or were admitted through the emergency department $(8 ; 4 \%)$.

Two thirds (152) of the congenital heart defects were classified as simple; one third (74) were classified as complex (Table 2). The more common simple lesions included ventricular septal defect and patent ductus arteriosus; the more common complex lesions included tetralogy of Fallot and endocardial cushion defect. At the time of the GS procedure, 52\% (73) of the simple lesions and $74 \%$ (54) of the complex lesions had undergone either complete or palliative repair; the average age at time of repair was $1.7 \pm 0.3$ years.

The overall mortality rate for the patients with simple congenital heart defects ( 152 procedures) was 9\% (13); that for the patients with complex lesions (74 procedures) was $19 \%(14 ; P \leq .05)$. The highest operative mortality rate among the cases with simple congenital defects was in patients with patent ductus arteriosus ( $26 \%$ of 43 operations); the highest mortality rate in the group with complex lesions was in patients with hypoplastic left heart syndrome or complex cardiac anomalies (both greater than 50\%). Preoperative correction of the congenital defect did not appear to significantly alter the operative mortality rates, being $12 \%, 14 \%$, and $12 \%$ for no, palliative, and complete repairs, respectively (Table 2 ).

The majority of the GS procedures were major intraabdominal or intrathoracic operations (156; $69 \%)$; the remainder $(70 ; 31 \%)$ were subcutaneous or vascular access procedures (Table 3 ). A wide spectrum of operations was performed; the most com-

Table 2. Frequency of Congenital Heart Defect, and State of Repair at Time of General Surgical Procedure

\begin{tabular}{|c|c|c|c|c|c|}
\hline & \multicolumn{3}{|c|}{ State of Repair } & \multirow[b]{2}{*}{ Total } & \multirow{2}{*}{$\begin{array}{c}\text { Mortality } \\
(\%)\end{array}$} \\
\hline & None & Partial & Complete & & \\
\hline \multicolumn{6}{|l|}{ Simple } \\
\hline Ventricular septal defect & 34 & 3 & 17 & 54 & $2(4)$ \\
\hline Patent ductus arteriosus & 11 & 1 & 31 & 43 & $11(26)$ \\
\hline Atrial septal defect & 14 & 0 & 6 & 20 & 0 \\
\hline Isolated pulmonic stenosis & 11 & 0 & 1 & 12 & 0 \\
\hline Coarctation of aorta & 1 & 0 & 7 & 8 & 0 \\
\hline Aortic stenosis & 2 & 2 & 2 & 6 & 0 \\
\hline Mitral insufficiency & 4 & 0 & 0 & 4 & 0 \\
\hline Aortic insufficiency & 2 & 0 & 0 & 2 & 0 \\
\hline Vascular ring & 0 & 1 & 1 & 2 & 0 \\
\hline Mitral stenosis & 0 & 0 & 1 & 1 & $1(100)$ \\
\hline No. of simple defects & 79 & 7 & 66 & 152 & \\
\hline No. of deaths & 4 & 0 & 9 & 13 & \\
\hline Mortality $(\%)$ & 5 & 0 & 14 & 9 & \\
\hline \multicolumn{6}{|l|}{ Complex } \\
\hline Tetralogy of Fallot & 3 & 8 & 9 & 20 & $3(20)$ \\
\hline \multicolumn{6}{|l|}{ Endocardial cushion } \\
\hline defects & 7 & 4 & 4 & 15 & $2(13)$ \\
\hline \multicolumn{6}{|l|}{ Transposition of great } \\
\hline vessels & 3 & 4 & 2 & 9 & $1(11)$ \\
\hline TAPVR & 0 & 0 & 6 & 6 & 0 \\
\hline Truncus arteriosus & 0 & 1 & 3 & 4 & $1(25)$ \\
\hline Hypoplastic left heart & 3 & 3 & 0 & 6 & $3(50)$ \\
\hline \multicolumn{5}{|l|}{ Double-outlet right ven- } & $1(25)$ \\
\hline Pulmonary atresia & 0 & 3 & 0 & 3 & $1(33)$ \\
\hline Ebstein's anomaly & 0 & 2 & 0 & 2 & 0 \\
\hline Tricuspid atresia & 1 & 1 & 0 & 2 & 0 \\
\hline Others* & 0 & 1 & 2 & 3 & $2(66)$ \\
\hline No. of complex defects & 19 & 28 & 27 & 74 & \\
\hline No. of deaths & 7 & 5 & 2 & 14 & \\
\hline Mortality $(\%)$ & 37 & 18 & 7 & 19 & \\
\hline \multicolumn{6}{|l|}{ Totals } \\
\hline No. of lesions & 98 & 35 & 93 & 226 & \\
\hline No. of deaths & 12 & 5 & 11 & 27 & \\
\hline Mortality $(\%)$ & 12 & 14 & 12 & 12 & \\
\hline
\end{tabular}

Abbreviation: TAPVR, total anomalous pulmonary venous return. *One each with atrioventricular canal, congenital aortic stenosis with complex anomalies, and complex anomalies not otherwise specified. 
Table 3. Type and Frequency of General Surgical Procedures

\begin{tabular}{lc}
\hline \multicolumn{1}{c}{ Type } & No. \\
\hline Minor & \\
Inguinal herniorrhaphy & 41 \\
Soft-tissue biopsy & 11 \\
Endoscopic procedures & 7 \\
Orchiopexy & 5 \\
Venous access procedures & 4 \\
Arteriography & 2 \\
Total & 70 \\
Mortality (\%) & $2(3)$ \\
Major & \\
Small bowel procedures* & 57 \\
Colonic procedurest & 27 \\
Fundoplication $\ddagger$ & 25 \\
CDH repair & 13 \\
Cholecystectomy & 6 \\
Abdominal herniorrhaphy§ & 5 \\
Noncardiac thoracic\| & 5 \\
Otherף & 18 \\
Total & 156 \\
Mortality (\%) & $25(16)$ \\
\hline
\end{tabular}

Abbreviation: $\mathrm{CDH}$, congenital diaphragmatic hernia.

*Includes enterectomy, enterostomy, enteroenterostomy, pyloromyotomy, hepaticoenterostomy, and tracheoesophageal fistula repair.

tIncludes appendectomy; right, left, sigmoid, total, and subtotal colectomy; creation or takedown of colostomy; and endorectal pullthrough.

‡Transabdominal approach.

§Includes omphalocele repair and incisional herniorrhaphy. |lincludes pulmonary lobectomy, open lung biopsy, and CDH repair.

IIncludes exploratory laparotomy (5), nephrectomy (3), open liver biopsy (3), perineal anoplasty (2), splenectomy (2), femoral patch angioplasty (1), renal artery revascularization (1), and total abdominal hysterectomy (1).

mon major procedure was a small bowel operation, and the most common minor procedure was an inguinal herniorrhaphy. Approximately two thirds of the operations were performed emergently (130) or urgently (17) $(58 \%$ and $7 \%$, respectively); only one third $(79 ; 35 \%)$ were performed electively.

Risk factors associated with postoperative mortality included young age, low operative weight, low Apgar score, presence of complex cardiac lesions, high $\Lambda$ SA score, urgent or emergent operation, major operation, and prolonged preoperative and postoperative hospital stay (Table 4). By stepwise multiple regression analysis, an ASA score of IV or higher, age of less than 6 months, preoperative hospital stay of 10 or more days, delivery at a tertiary care center, and emergency operations were found to be independent predictors of postoperative mortality.

Perhaps the most accurate predictor of postoperative mortality was the preoperative ASA score (Table $5)$. There were no operative deaths among the patients in ASA classes I and II; the mortality progressively increased for patients in ASA class III or higher
Table 4. Independent Variables Associated With Postoperative Survival

\begin{tabular}{lcl} 
& $F$ & $P$ Value \\
\hline General patient characteristic & & \\
Age* & 13.83 & .001 \\
Weight & 4.13 & .04 \\
Apgar at 1 min & 5.82 & .01 \\
$\quad$ Admission pattern* & 7.97 & .005 \\
Characteristics of the congenital & & \\
$\quad$ heart defect & & \\
Complex $v$ simple defect & 3.84 & .05 \\
Characteristics of the surgical & & \\
$\quad$ procedure & & \\
ASA score* & 67.96 & .0001 \\
Urgency of operation* & 11.13 & .001 \\
Major $v$ minor procedure & 8.18 & .004 \\
LOS before procedure* & 14.76 & .0002 \\
LOS after procedure & 8.81 & .003 \\
\hline
\end{tabular}

Note. The following were not statistically significant: birth weight, gestational age, Apgar at $5 \mathrm{~min}$, sex, race, surgical correction of the congenital defect, presence of cyanosis, and number of cardiac medication.

Abbreviation: LOS, length of stay.

* Statistically independent predictors of postoperative outcome.

(Fig 1). The urgency of the GS procedure was also an independent risk factor for postoperative mortality. The mortality for patients operated on electively was $4 \%$; that for patients with emergency operations was $18 \%(P \leq .05)$. The pattern of referral to the GS service was also an independent risk factor, being associated with $30 \%$ mortality among patients transferred from a tertiary care birth center, and 6\% mortality among those referred from an outpatient setting $(P \leq .05)$.

The overall mortality rate for patients aged 6 months or younger was $15 \%$ (Table 1); that for

Table 5. Operative Mortality for Patients Undergoing General Surgical Procedures

\begin{tabular}{lcc}
\hline & $\begin{array}{c}\text { Minor Procedures } \\
(\%)\end{array}$ & $\begin{array}{c}\text { Major Procedures } \\
(\%)\end{array}$ \\
\hline ASA score ${ }^{*}$ & & $0 / 2$ \\
I & $0 / 1$ & $0 / 29$ \\
II & $0 / 28$ & $3 / 61$ \\
III & $0 / 27$ & $16 / 41(39)$ \\
IV (5) & $2 / 4(50)$ & $5 / 7(71)$ \\
V & - & $3 / 40(7)$ \\
Urgency of operation* & & $0 / 10$ \\
Elective & $0 / 39$ & $22 / 106(21)$ \\
Urgent & $0 / 7$ & \\
Emergency & $2 / 24(8)$ & $6 / 58(10)$ \\
Admission pattern & & $0 / 8$ \\
Outpatient & $0 / 49$ & $12 / 70(17)$ \\
Emergency room & - & $7 / 20(35)$ \\
Outside hospital & $1 / 14(7)$ &
\end{tabular}

*P $\leq .05$ by $\chi^{2}$ analysis.

tASA data missing for 10 minor procedures and 13 major procedures. 


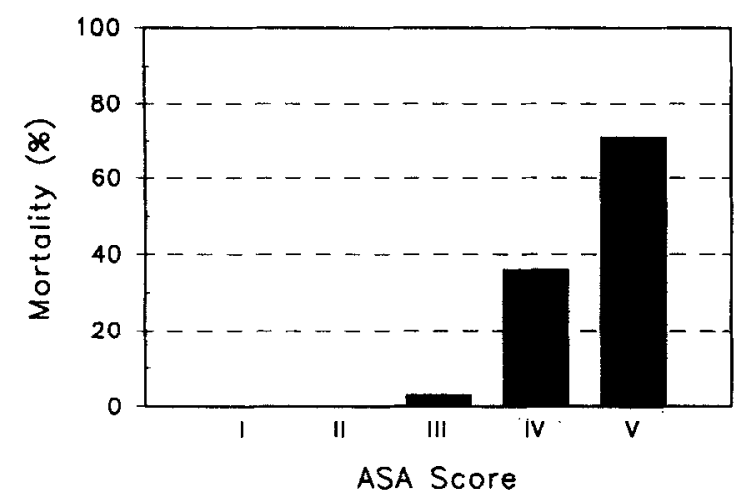

Fig 1. Predictive value of the ASA physical status class on postoperative mortality after general surgical procedures in patients with congenital heart disease.

patients older than 6 months was $7 \%(P \leq .05)$. Patients under 6 months of age had a higher preoperative ASA score, were more frequently operated on urgently or emergently, were more often transferred from an outside hospital or a tertiary care birth center, and were hospitalized longer both before and after the operation. In this group of patients, operative weight of less than $2.4 \mathrm{~kg}$ was an additional independent risk factor for mortality. The mortality rate for patients who weighed less than $2.4 \mathrm{~kg}$ was $32 \%$ ( 10 of 31 ); that for patients who weighed more than $2.4 \mathrm{~kg}$ was $13 \%$ (9 of 68 patients; $P \leq .05$ ). The 1-minute Apgar score was another independent risk factor. Patients whose score was less than 4 had an operative mortality rate of $28 \%$ (13 of 46 ); those whose score was greater than 4 had an operative mortality rate of $11 \%$ ( 6 of $63 ; P \leq .05$ ). Two neonates with simple heart disease died after undergoing a minor surgical procedure. Both had multiple medical problems and protracted hospitalizations in the intensive care unit. Both underwent ligation of a patent ductus arteriosus weeks before the emergency inguinal herniorrhaphy because of concern over bowel obstruction or strangulation. Neither was discharged home; both died of respiratory failure and sepsis, more than 1 month after the operation.

\section{DISCUSSION}

The incidence of CHD is approximately $0.8 \%$ of live births; the surgical management has witnessed marked improvement in the past decade. ${ }^{2-5}$ This fact, along with continued advances in medical management has resulted in an ever-increasing population of CHD patients living into adulthood ${ }^{6,7}$ In addition, especially in pediatric tertiary care centers, a significant number of patients are referred for urgent or emergent management of noncardiac problems that arise either during the management of the heart defect or thereafter. The operative mortality rate of noncardiac procedures in patients with congenital heart defects is not known, although the perioperative anesthetic morbidity has been reported to be approximately $47 \% .^{8}$ The purpose of the present study was to evaluate the operative mortality in patients with CHD who undergo GS procedures, to define risk factors associated with the increased postoperative mortality, and to propose strategies that might improve the operative risk.

The operative mortality rate in this study was $12 \%$ (16\% for major procedures, $3 \%$ for minor proce dures). These statistics are higher than those associated with corrective cardiac procedures, for which the reported operative mortality rate approximates $5 \%{ }^{9}$ Our statistics also exceed those associated with GS procedures in otherwise healthy children, for which the mortality rate is less than $1 \%$.

By stepwise multiple regression analysis, several risk factors were identified that could account for this seemingly high mortality. The ASA score, the urgency of the operation, and the referral pattern were all found to be statistically independent predictors of postoperative outcome. Hence, physiologically wellcompensated patients referred from the outpatient setting would be expected to have an acceptable risk for undergoing elective GS procedures. In fact, there was only one death among the 65 elective cases performed for patients in ASA classes I through III (overall mortality, $1.5 \%$ ) a result comparable to those of studies in patients without underlying CHD.

A second group of patients, typical of those cared for in tertiary care centers, had increased operative mortality. Generally, these patients were operated on urgently or emergently, underwent major intraabdominal or intrathoracic procedures, and were referred from acute care settings such as tertiary care birthing centers, emergency departments, or outside hospitals. The operative mortality in this group was high, as exemplified by the 41 emergency cases, classified as ASA IV or V, in which the operative mortality was $51 \%$ (21 deaths). In this latter group, identification and reversal of risk factors may decrease operative mortality.

Several risk factors, such as young age, prolonged hospital stay, and delivery at a tertiary care center, are not amenable to reversal before surgery, and must be accepted as part of the overall health profile of this high-risk population. However, several aspects of the preoperative and postoperative care should be addressed as a means of decreasing the operative risk, including early referral of patients with GS problems, emphasis on good preoperative nutrition, and control 
of sepsis. Finally, in very young patients who are physiologically compromised, elective or semielective surgical intervention should be delayed when possible. Neither the presence of simple heart defects nor the repair of the congenital defect was independently associated with reduction of operative mortality, implying that the patient's physiological state is the primary determinant of postoperative outcome.

\section{REFERENCES}

1. Goldman L, Caldera DL, Nussbaum SR, et al: Multifactorial index of cardiac risk in noncardiac surgical procedures. $\mathrm{N}$ Engl $\mathrm{J}$ Med 297:845-850, 1977

2. Lupinetti FM, Bove EL, Minich LL, et al: Intermediate-term survival and functional results after arterial repair for transposition of the great arteries. J Thorac Cardiovasc Surg 103:421-427, 1992

3. Meliones JN, Snjder AR, Bove EL, et al: Longitudinal results after first-stage palliation for hypoplastic left heart syndrome. Circulation 82:IV151-IV156, 1990

4. Fontan F, Kirklin JW, Fernandez G, et al: Outcome after a "perfect" Fontan operation. Circulation 81:1520-1536, 1990

5. Di Donato RM, Jonas RA, Lang P, et al: Neonatal repair of tetralogy of Fallot with and without pulmonary atresia. J Thorac Cardiovasc Surg 101:126-137, 1991

6. Perloff JK: Congenital heart disease in adults. A new cardiovascular subspecialty. Circulation 84:1881-1890, 1991

7. Cetta F, Lichtenberg RC, Clark SE: Adults with congenital heart disease. Compr Ther 18:33-37, 1992

8. Strafford MA, Henderson KH: Anesthetic morbidity in congenital heart disease patients undergoing non-cardiac surgery. Anesthesiology 75:A1056, 1991 (abstr)

9. Sholler GF, Celermajer JM: Cardiac surgery in the first year of life: The effect on weight gains of infants with congenital heart disease. Aust Paediatr J 22:305-308, 1986 